\title{
Decorated MCM-41/polyethylene hybrids: Crystalline Details and Viscoelastic Behavior
}

\author{
María L. Cerrada*1 ${ }^{1}$ Ernesto Pérez ${ }^{1}$, João P. Lourenço ${ }^{2}$, Artur Bento ${ }^{3}$, \\ M. Rosário Ribeiro*3
}

${ }^{1}$ Instituto de Ciencia y Tecnología de Polímeros (ICTP-CSIC). Juan de la Cierva 3, 28006 Madrid, Spain ${ }^{2}$ Centro de Investigação em Química do Algarve (CIQA). Faculdade de Ciências e Tecnologia-Universidade do Algarve. Campus de Gambelas, 8005-139 Faro, Portugal.

${ }^{3}$ Instituto de Ciência e Engenharia de Materiais e Superfícies (ICEMS) \& Departamento de Engenharia Química. Instituto Superior Técnico - Universidade Técnica de Lisboa. Av. Rovisco Pais 1, 1049-001 Lisboa, Portugal *Corresponding authors.

Tel.: +34-915622900; Fax: +34-915644853; E-mail address: mlcerrada@ictp.csic.es

Tel.: +351-218417325; Fax: +351-218419198; E-mail address: rosario@ist.utl.pt

Table S1. Parameters of the MCM-41 mesoporous materials used as fillers.

\begin{tabular}{ccccc}
\hline Sample & $\begin{array}{c}\text { Modifying agent } \\
\text { content } \\
(\mathrm{mmol} / \mathrm{g})\end{array}$ & $\begin{array}{c}\mathrm{S}_{\mathrm{BET}} \\
\left(\mathrm{m}^{2} / \mathrm{g}\right)\end{array}$ & $\begin{array}{c}\mathrm{V}_{\mathrm{p}} \\
\left(\mathrm{cm}^{3} / \mathrm{g}\right)\end{array}$ & $\begin{array}{c}\mathrm{D}_{\mathrm{p}} \\
(\AA)\end{array}$ \\
\hline MCM-41 & - & $870 \pm 5$ & 0.72 & 33 \\
MCM-41 & & & & \\
$\begin{array}{c}\text { (UA/TIBA }) \\
\text { MCM-41 }\end{array}$ & 2.0 & $625 \pm 30$ & 0.33 & 21 \\
$(\mathrm{UA} / \mathrm{TIBA})$ & 5.9 & $295 \pm 5$ & 0.13 & 18 \\
\hline
\end{tabular}

$\mathrm{S}_{\mathrm{BET}}$ : specific surface area, $\mathrm{V}_{\mathrm{p}}$ : specific pore volume (calculated at the top of the adsorption step), $\mathrm{D}_{\mathrm{p}}$ : average pore diameter estimated by Gurvitsch method $\left(D_{p}=4 V_{p} / S_{B E T}\right)$. 


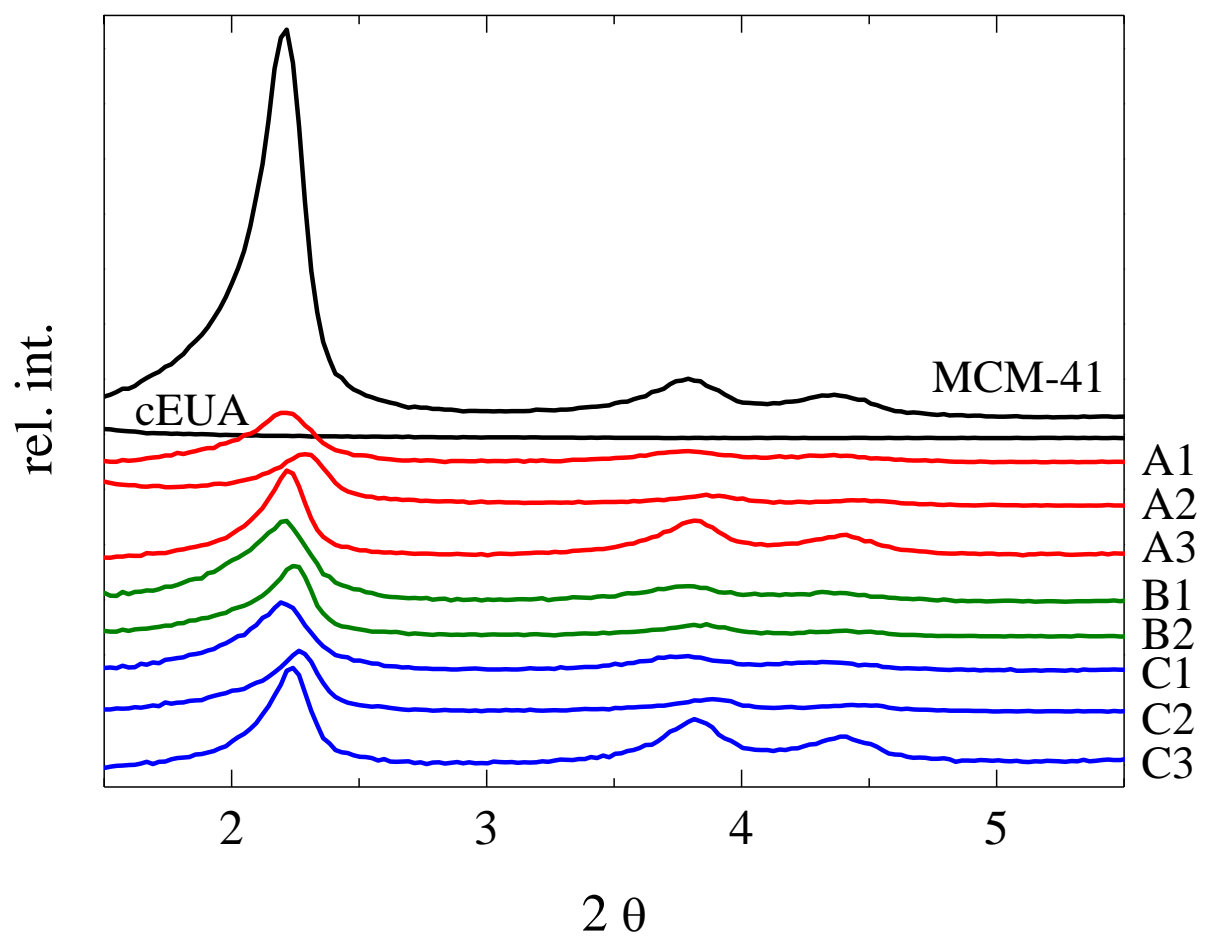

Figure S1. X ray profiles at room temperature at the middle angle region for all the synthesized hybrids as well as for MCM-41 and copolymer cEUA, these two used as references.

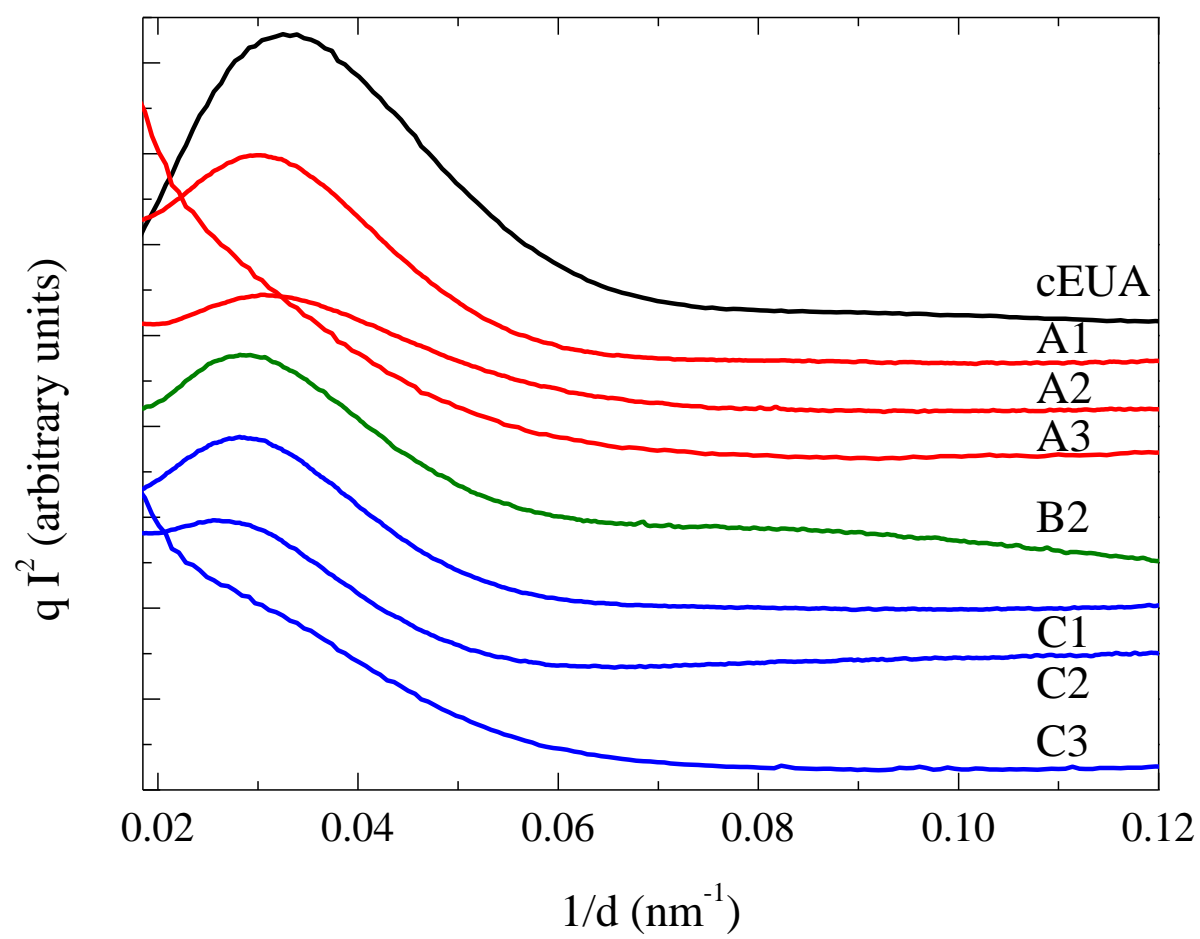

Figure S2. SAXS diffraction patterns at room temperature for the cEUA copolymer and the different hybrids. 

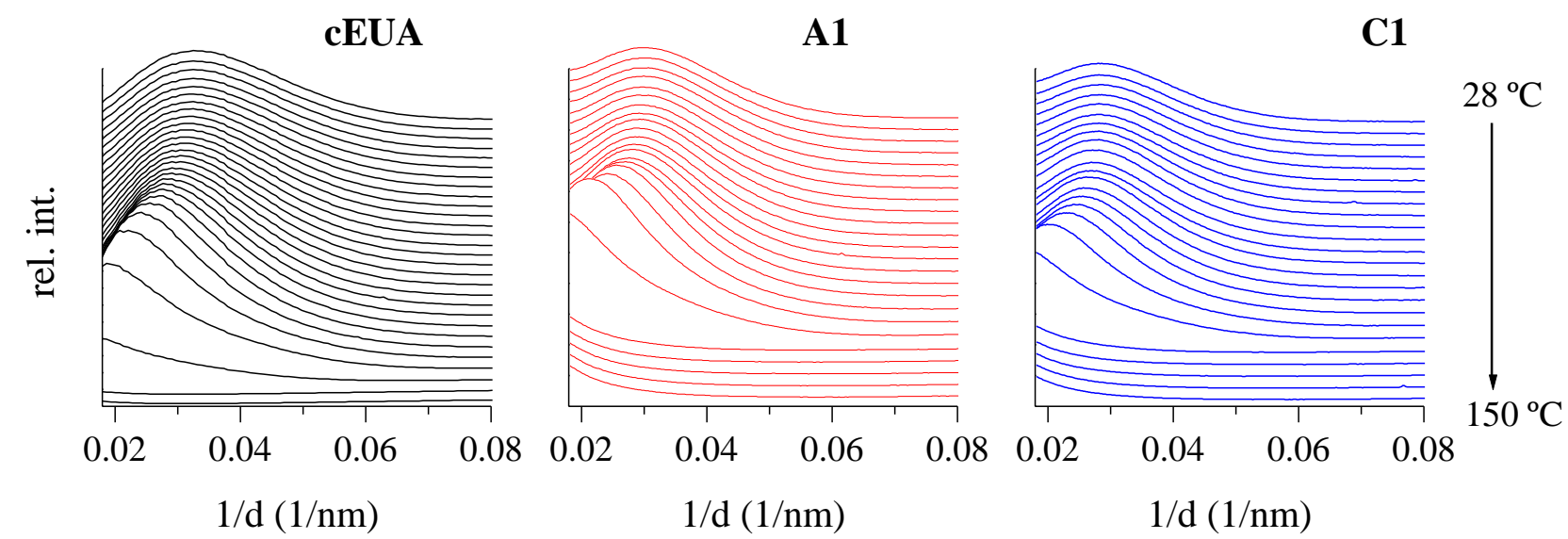

Figure S3. Real-time SAXS profiles, obtained with synchrotron radiation, for cEUA copolymer and two of the hybrids in a melting experiment at $8^{\circ} \mathrm{C} / \mathrm{min}$. Only one frame every three is plotted, for clarity.

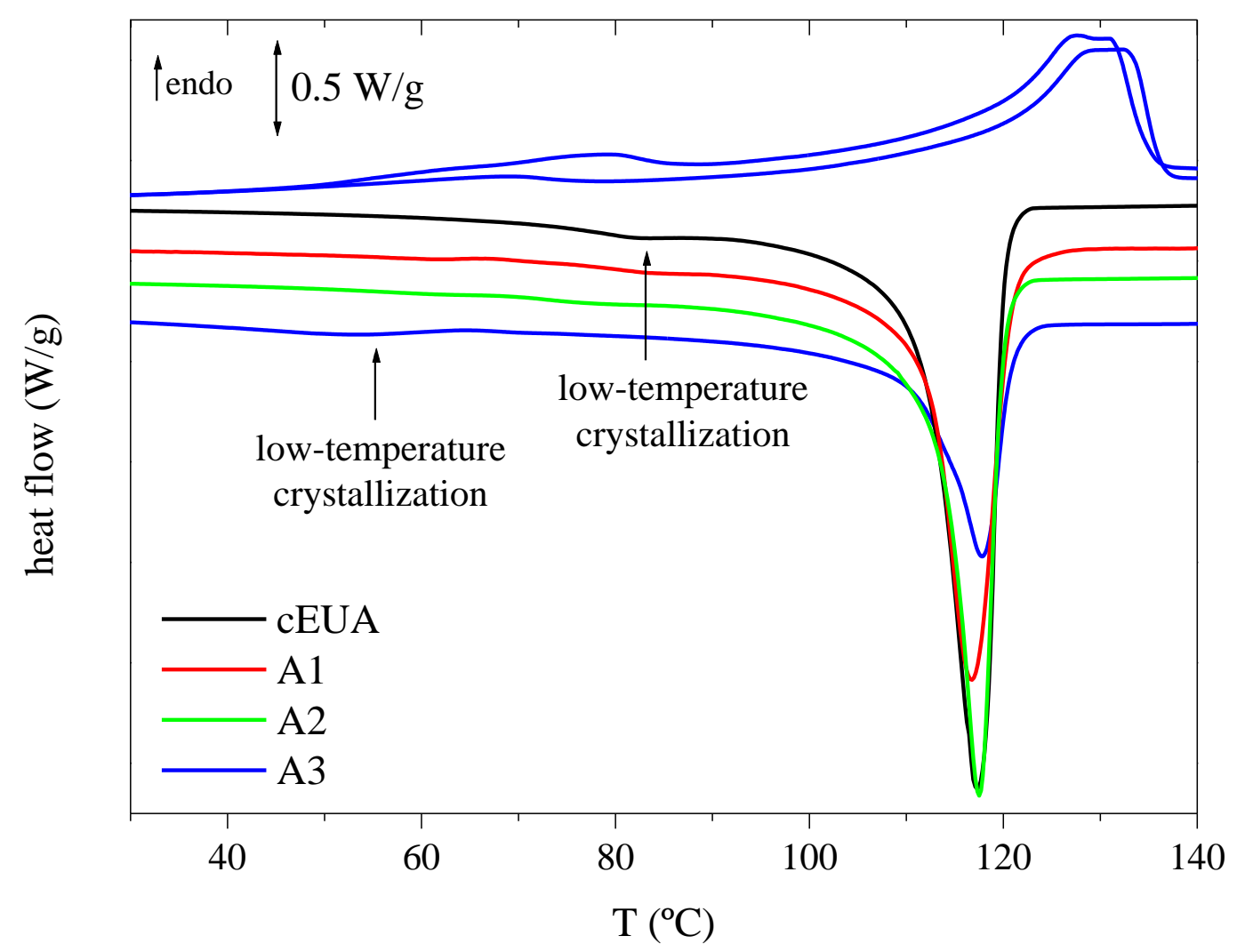

Figure S4. Complete DSC measurement for A3: first and second melting and crystallization runs. Crystallization of cEUA, A1 and A2 has been incorporated for comparative reasons. 


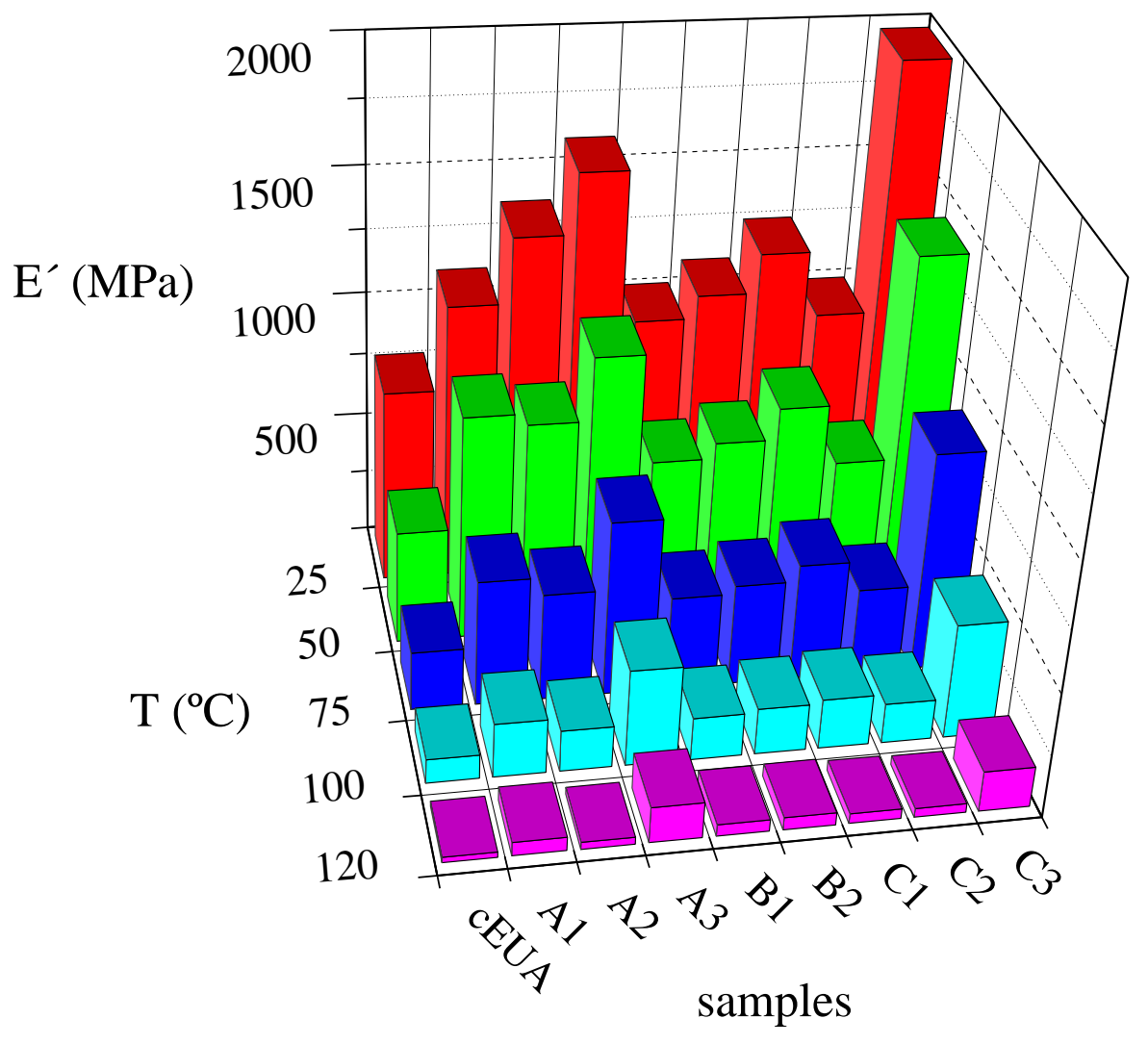

Figure S5. Variation of the storage modulus $\left(\mathrm{E}^{\prime}\right)$ at the indicated temperatures for cEUA and the different hybrids analyzed.

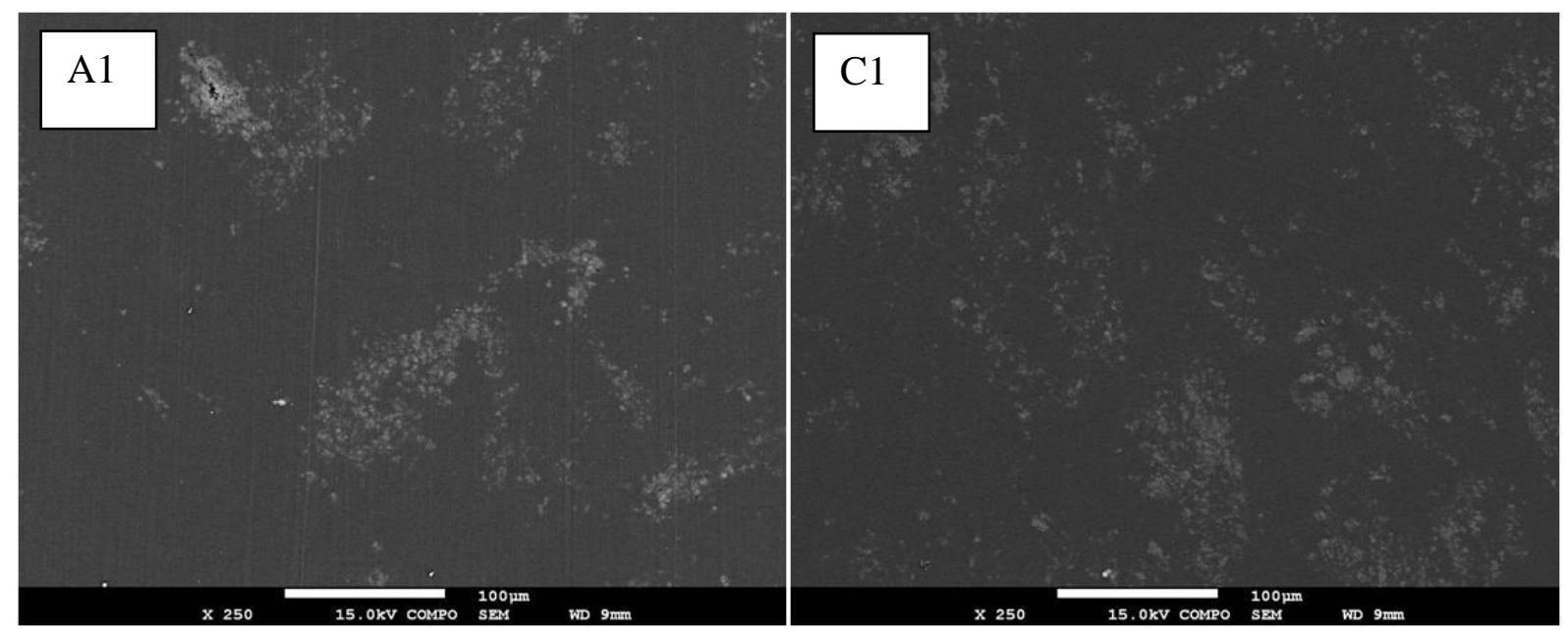

Figure S6. SEM micrographs for the A1 and C1 hybrids. 